\title{
Resistência de bactérias ácido-láticas a bacteriófagos provenientes de unidades de processamento de queijo Coalho
}

\author{
Phage resistance of acid lactic bacteria isolated from Coalho cheese industries
}

\author{
Cristiane Pereira de LimaI Laura Maria Bruno ${ }^{I I}$ Evânia Altina Teixeira de FigueiredoII

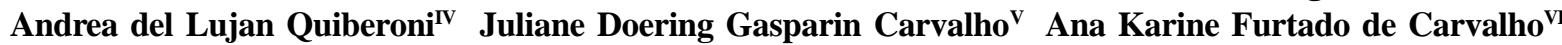

\section{RESUMO}

Este trabalho teve como objetivos isolar bacteriófagos de amostras de leite, soro e queijo de Coalho e avaliar a resistência de cepas de Lactobacillus paracasei, pertencentes à Coleção de Micro-organismos de Interesse para a Agroindústria Tropical da Embrapa Agroindústria Tropical, aos fagos isolados. Posteriormente, a resistência destas cepas a fagos específicos para L. paracasei, da Coleção do Instituto de Lactología Industrial - INLAIN (Santa Fe, Argentina), também foi avaliada. As amostras para isolamento dos fagos foram obtidas em quatro unidades de processamento de queijo de Coalho, sendo duas artesanais e duas industriais, localizadas no Estado do Ceará. Para o isolamento dos bacteriófagos, foi empregado o teste de lise celular (spot), enquanto que a resistência das culturas aos fagos foi avaliada pelos testes de capacidade de produção de ácido e avaliação da turbidez. As cepas avaliadas foram resistentes aos bacteriófagos provenientes das unidades de processamento de queijo de Coalho e aos bacteriófagos da Coleção do INLAIN. Os resultados obtidos indicaram que as culturas láticas testadas, resistentes aos bacteriófagos, podem ser utilizadas na composição de fermento lático destinado à elaboração de queijo de Coalho, a partir de leite pasteurizado.

Palavras-chave: produtos lácteos fermentados, cultura lática, vírus.

\section{ABSTRACT}

The objectives of this research were to isolate bacteriophages from milk samples, whey and Coalho cheese and to evaluate the resistance of strains of Lactobacillus paracasei from the Collection of Microorganisms of Interest for the Tropical Agroindustry, belonging to Embrapa Tropical Agroindustry, to isolate phages. The strains resistance to specific L. paracasei phages from the collection of the Instituto de Lactología Industrial - INLAIN (Santa Fe, Argentina) was also evaluated. Samples for phage isolation were from four Coalho cheese processing units, two artisanal and two industrial, localized in the state of Ceará. Spot test was employed for bacteriophages isolation, while the culture phage resistance was evaluated by the acid production and turbidity tests. The strains were resistant both to phages isolated from Coalho cheese processing units and phages from collection of INLAIN. The results showed that lactic cultures evaluated here were resistant to bacteriophages and they can be used in the composition of lactic cultures specifically for Coalho cheese manufacture from pasteurized milk.

Key words: fermented dairy products, lactic culture, virus.

\section{INTRODUÇÃO}

Bactérias ácido-láticas (BAL) constituem um grupo de micro-organismos Gram-positivos comumente utilizados na indústria de laticínios na elaboração de produtos lácteos fermentados, como queijos e iogurtes (MADERA et al., 2003). Produzem um grande número de enzimas glicolíticas, proteolíticas e lipolíticas, transformando os nutrientes do meio em

\footnotetext{
${ }^{I}$ Instituto Federal de Ciência e Tecnologia Baiano (IFBAIANO), 45680-000, Uruçuca, BA, Brasil. E-mail: cristiane.pereira@hotmail.com. Autor para correspondência.

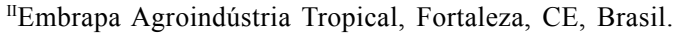

IIIDepartamento de Tecnologia de Alimentos, Universidade Federal do Ceará (UFC), Fortaleza, CE, Brasil.

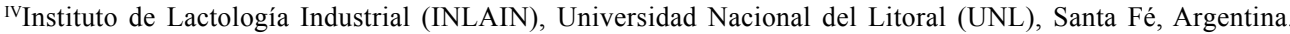

${ }^{v}$ Departamento de Tecnologia de Alimentos, UFC, Fortaleza, CE, Brasil.

${ }^{\mathrm{VI} E s c o l a ~ d e ~ E n g e n h a r i a ~ d e ~ L o r e n a ~(E E L), ~ U n i v e r s i d a d e ~ d e ~ S a ̃ o ~ P a u l o ~(U S P), ~ S a ̃ o ~ P a u l o, ~ S P, ~ B r a s i l . ~}$
} 
compostos com propriedades sensoriais complexas, os quais modificam gradativamente a textura e o aroma dos alimentos fermentados (PIARD et al., 1999).

BAL tem sido isoladas e caracterizadas de leite e queijos artesanais, como o queijo de Coalho, visando à seleção de culturas láticas para a obtenção de produtos de qualidade (BRUNO et al., 2004; CARVALHO et al., 2007). Entre as características tecnológicas que as BAL devem apresentar para serem utilizadas na composição de um fermento lático, destacase a sua resistência à infecção por bacteriófagos.

Bacteriófagos ou fagos são vírus intracelulares obrigatórios de bactérias. Cada fago é específico para uma determinada espécie bacteriana, sendo incapazes de infectar outras (HAGENS \& OFFERHAUS, 2008). A infecção por bacteriófagos na indústria de produtos fermentados pode ocasionar a diminuição da capacidade de acidificação das culturas láticas, resultando em problemas como a ausência da fermentação e má dessoragem do queijo, ocasionando substanciais perdas econômicas (ALLISON \& KLAENHAMMER, 1998; QUIBERONI, et. al., 2003; GUGLIELMOTTI et. al., 2009).

O persistente problema de infecção por fagos em indústrias de laticínios tem fomentado a demanda por pesquisas para o desenvolvimento de fermentos láticos compostos por culturas láticas resistentes a bacteriófagos (MADERA et al., 2003; QUIBERONI et al., 2010). Nesse contexto, o presente trabalho teve como objetivo isolar bacteriófagos de amostras de leite, soro e queijo de Coalho de quatro unidades de processamento de queijo de Coalho do Ceará e avaliar a resistência de cepas de Lactobacillus paracasei, pertencentes à coleção de microorganismos da Embrapa Agroindústria Tropical, frente aos fagos isolados e a fagos da Coleção do Instituto de Lactología Industrial - INLAIN (Santa Fe, Argentina).

\section{MATERIAL E MÉTODOS}

Um total de 36 amostras, sendo 12 de leite, 12 de soro (oriundo do processo de fabricação dos queijos) e 12 amostras de queijo Coalho, foi utilizado para o isolamento dos bacteriófagos. As amostras foram coletadas em quatro unidades produtoras de queijo de Coalho localizadas no estado do Ceará, sendo duas produtoras de queijos de Coalho artesanal e duas, de queijo de Coalho industrial, no período de maio a julho de 2009.

A obtenção de filtrados suspeitos de conter fagos foi realizada conforme SVENSSON \& CHRISTIANSSON (1991). Uma alíquota de $10 \mathrm{~g}$ de cada queijo de Coalho foi diluída em $90 \mathrm{~mL}$ de uma solução de citrato de sódio $2 \%$ (Vetec) e homogeneizada em homogeneizador tipo Stomacher (Seward, 400). As demais amostras (leite e soro) foram utilizadas diretamente, sem diluições. Após o ajuste do $\mathrm{pH}$ para 4,6 , as amostras foram centrifugadas (5000 $\mathrm{g} / 20$ minutos) em centrífuga Biofuge Stratos (Heraeus Instruments) para remoção de grandes partículas (proteínas) e, em seguida, filtradas a vácuo $(0,45 \mu \mathrm{m})$, para a remoção de bactérias. Para diferenciar o efeito dos bacteriófagos dos outros agentes inibidores, uma alíquota de cada filtrado foi tratada termicamente a $90^{\circ} \mathrm{C}$ por 15 minutos em banho-maria (Quimis - Q215M2). Este aquecimento inativa os fagos, mas não tem efeito sobre outros agentes inibidores, como, por exemplo, antibióticos. Os filtrados, assim obtidos, foram utilizados para a pesquisa de fagos.

Três cepas de referência de BAL (Streptococcus thermophilus ATCC 19258, Lactococcus lactis ATCC 14579, Lactobacillus paracasei ATCC BAA-52); 11 cepas de Lactobacillus paracasei, previamente isoladas de queijos de Coalho artesanais produzidos no Ceará, e pertencentes à Coleção de Micro-organismos de Interesse para a Agroindústria Tropical da Embrapa Agroindústria Tropical; e uma cepa de Escherichia coli ATCC 11775 (controle) foram empregadas para detectar a presença de fagos nas amostras.

O teste de lise celular (spot) foi empregado para o isolamento de bacteriófagos, enquanto que a resistência das culturas aos fagos foi avaliada pelos testes de capacidade de produção de ácido e de turbidez, todos descritos conforme SVENSSON \& CHRISTIANSSON (1991). No teste de lise celular, a uma alíquota de $50 \mu \mathrm{L} \mathrm{de} \mathrm{CaCl}_{2} 1 \mathrm{M}$ foi adicionado $100 \mu \mathrm{L}$ da cultura lática previamente ativada em caldo Man, Rogosa e Sharpe - MRS (Acumedia), sob aerobiose, na temperatura de $37^{\circ} \mathrm{C}$ por 24 horas. Esta mistura foi vertida em um tubo contendo 2,5mL de ágar MRS semisólido $(0,6 \%)$ e agitada levemente, sendo, então, vertida sobre a superfície de uma placa contendo uma fina camada de ágar MRS-Ca (10mM). Após a solidificação do ágar, uma gota (aproximadamente $10 \mu \mathrm{L}$ ) de cada filtrado obtido foi adicionada sobre esta base e, em seguida, as placas foram incubadas, sob aerobiose, a $35^{\circ} \mathrm{C}$ (mesofílicos) ou $42^{\circ} \mathrm{C}$ (termofílicos), por 48 horas. O mesmo procedimento foi utilizado para a cepa de $\boldsymbol{E}$. coli, com substituição do ágar MRS por ágar infuso de cérebro e coração $(\mathrm{BHI})$.

Para o teste de turbidez, em um tubo contendo $5 \mathrm{~mL}$ de MRS - Ca, foi acrescentado $1 \%$ da cultura previamente ativada e $100 \mu \mathrm{L}$ do filtrado obtido. Os tubos foram incubados, sob aerobiose, a $35^{\circ} \mathrm{C}$ ou $42^{\circ} \mathrm{C}$ por 24 horas. $\mathrm{O}$ controle foi realizado pela 
incubação da cultura sem o filtrado, nas mesmas condições citadas. $\mathrm{O}$ crescimento da cultura, ou seja, a turbidez do meio foi acompanhada visualmente em comparação com o tubo controle, durante intervalos regulares de 6 horas. $\mathrm{O}$ mesmo procedimento foi realizado para o filtrado tratado termicamente para, dessa forma, diferenciar o efeito dos bacteriófagos de efeitos de outros agentes inibidores, caso estivessem presentes nas amostras.

O teste de produção de ácido foi realizado para verificar a capacidade acidificante das culturas na presença e ausência do filtrado suspeito de conter fagos. Foram preparados três frascos contendo $50 \mathrm{~mL}$ de leite desnatado reconstituído (LDR) $10 \%$ e: a) $1 \mathrm{~mL}$ do filtrado não tratado termicamente e $1 \%$ do inóculo da cultura a ser testada; b) $1 \mathrm{~mL}$ do filtrado tratado termicamente e $1 \%$ do inóculo da cultura a ser testada; c) apenas $1 \%$ do inóculo da cultura a ser testada (controle). Antes da incubação, o pH e a acidez do meio foram determinados. $\mathrm{O} \mathrm{pH}$ foi mensurado em potenciômetro digital (PHTEK modelo PHS-3B) e a acidez foi determinada pelo método titulométrico com solução de hidróxido de sódio (Vetec) $0,1 \mathrm{~N}$, conforme a metodologia AOAC 935.17 (AOAC, 1997). Os frascos foram incubados a $35^{\circ} \mathrm{C}$ ou $42^{\circ} \mathrm{C}$ e, após 6 horas, o $\mathrm{pH}$ e a acidez foram novamente mensurados. Os resultados foram expressos em percentuais de acidez em ácido lático (g 100g-1 amostra).

A avaliação da resistência das cepas de Lactobacillus paracasei a fagos específicos para $\boldsymbol{L}$. paracasei foi realizada de acordo com CAPRA (2007). Oito bacteriófagos da Coleção do Instituto de Lactología Industrial - INLAIN (Santa Fe, Argentina) foram empregados (Tabela 1). Uma alíquota de $0,2 \mathrm{~mL}$ da cultura previamente ativada foi inoculada em um tubo contendo $5 \mathrm{~mL}$ de caldo MRS-Ca. Em seguida, $100 \mu \mathrm{L}$ da solução fágica foi adicionada a este mesmo tubo e incubada a $37^{\circ} \mathrm{C}$. Um tubo contendo somente o inóculo bacteriano foi utilizado como controle de

Tabela 1 - Bacteriófagos utilizados para avaliar a resistência de Lb. paracasei.

\begin{tabular}{lc}
\hline & \\
Isolados de amostras & ATCC \\
\hline MLC-A & J-1 \\
PMLC-A & \\
MLC-A 2 & \\
MLC-A 7R & \\
MLC-A 8 & \\
MLC-A 17 & \\
MLC-A 19 &
\end{tabular}

crescimento. A observação visual do aumento de turbidez foi efetuada pela comparação do tubo controle com os tubos contendo os bacteriófagos por um período de tempo tal que permitisse um bom desenvolvimento do cultivo controle (aproximadamente 6 horas). Se, neste primeiro repique, não fosse observada diferença de turbidez entre o tubo controle e o tubo com o fago após o período de incubação, dois repiques adicionais, partindo da primeira série de tubos, eram realizados e o mesmo procedimento de incubação era repetido. Dessa forma, se a cultura fosse pouco sensível ao fago testado, os repiques possibilitariam a propagação do fago, aumentando o seu título e consequentemente favorecendo a lise do cultivo.

\section{RESULTADOS E DISCUSSÃO}

No teste de lise celular, após o crescimento bacteriano, quando o micro-organismo testado é sensível ao fago presente na amostra, este fago lisa as células hospedeiras e infecta as células vizinhas, formando um halo de lise celular em torno do ponto em que o filtrado suspeito de conter bacteriófagos foi inoculado. Nenhuma cepa de BAL avaliada apresentou sensibilidade aos fagos que poderiam estar presentes nos filtrados analisados, uma vez que não houve visualização de halos de lise celular nas placas referentes a estas culturas. Isto pode ter ocorrido tanto pela resistência natural das bactérias aos fagos presentes, quanto em decorrência de não haver fagos nestas amostras. Dessa forma, não foi possível isolar bacteriófagos específicos para as bactérias láticas testadas: Streptococcus thermophilus, Lactococcus lactis e Lactobacillus paracasei.

De acordo com HAGENS \& OFFERHAUS (2008), bacteriófagos são os organismos mais abundantes do ambiente e estão presentes em alto número na água e em alimentos de várias origens. Então, para refutar a hipótese da não existência de bacteriófagos nos filtrados, o mesmo teste foi realizado com cepa de Escherichia coli, a qual demonstrou ser sensível aos fagos dos filtrados oriundos das amostras de soro das unidades de processamento artesanal (Figura 1).

Apesar do isolamento de fago específico para $\boldsymbol{E}$. coli não ser o aspecto principal deste trabalho, este é um resultado relevante, uma vez que o uso de fagos líticos no controle de bactérias tem sido atualmente abordado por vários pesquisadores (ALLWOOD et al., 2004; O'FLYNN et al., 2004; MALLOVE, 2010).

Os resultados do teste de produção de ácido em termos de acidez e $\mathrm{pH}$ podem ser observados nas 


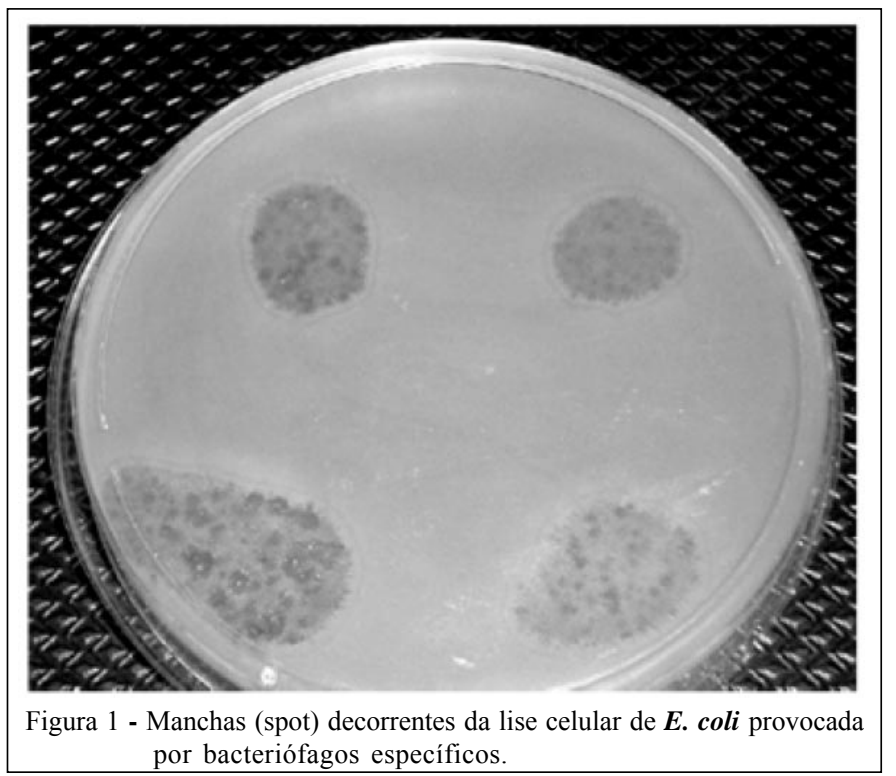

figuras 2 e 3, respectivamente, nas quais está representada a redução máxima da quantidade de ácido produzido (\% de ácido lático) e do $\mathrm{pH}$ do leite fermentado pela cultura quando inoculada juntamente com os filtrados suspeitos de conter bacteriófagos, após 6 horas de incubação. De acordo com SVENSSON \& CRHISTIANSON (1991), para uma cultura ser considerada resistente a fagos, é necessário que a redução na quantidade de ácido produzido e de $\mathrm{pH}$ da cultura, quando inoculada juntamente com o filtrado suspeito de conter bacteriófagos, sejam inferiores a
$10 \%$ e 0,2 , respectivamente. Todas as culturas láticas avaliadas foram resistentes aos fagos presentes nas amostras, visto que a redução na quantidade de ácido produzido (\% de ácido lático) e do $\mathrm{pH}$ das culturas inoculadas com os filtrados suspeitos de conter bacteriófagos não ultrapassaram 3,6\% (Figura 2) e 0,18 (Figura 3), respectivamente.

No teste de turbidez, foi observado que todas as cepas avaliadas apresentaram o mesmo desenvolvimento do controle, quando inoculadas juntamente com os filtrados suspeitos de conter

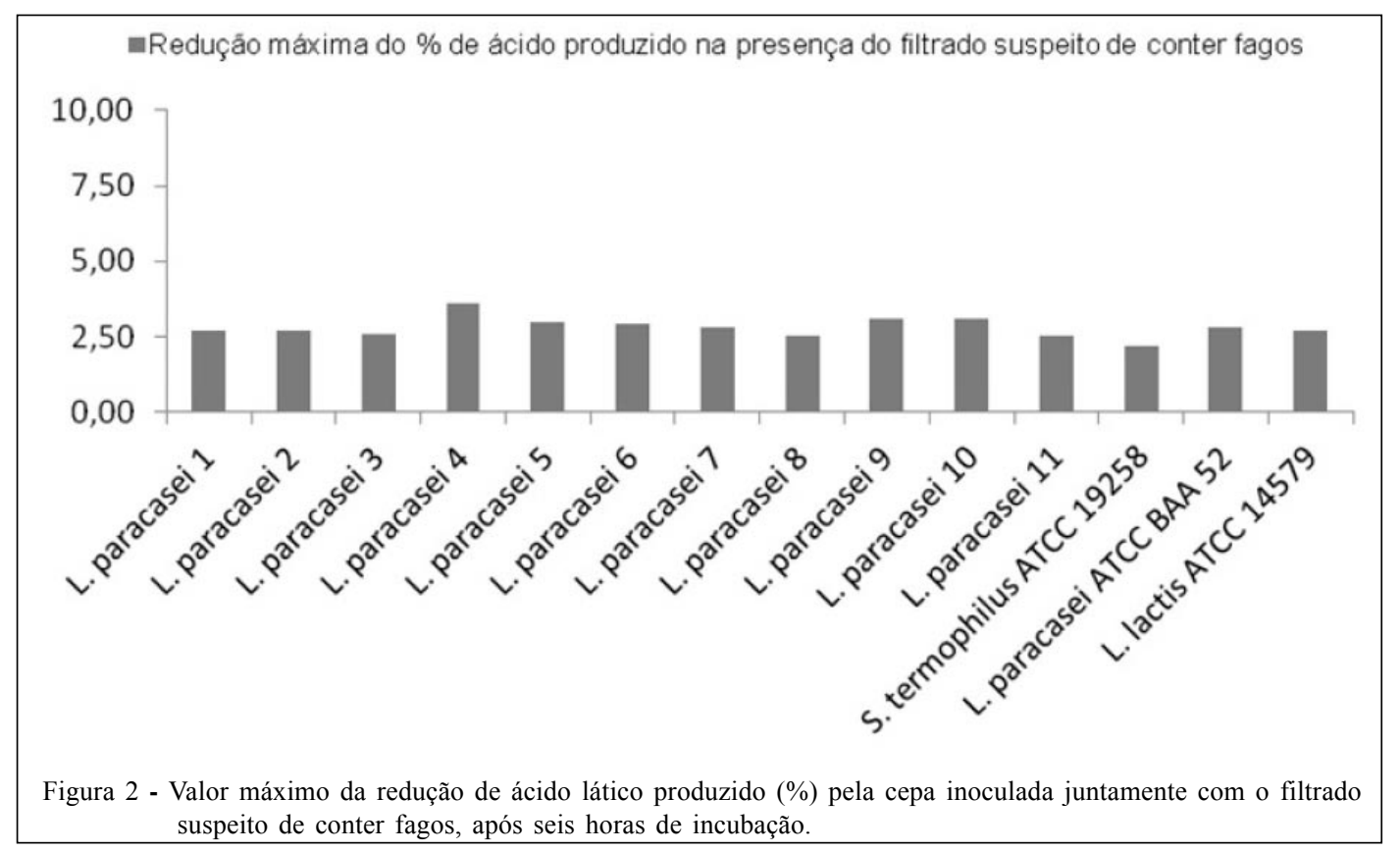

Ciência Rural, v.42, n.6, jun, 2012. 


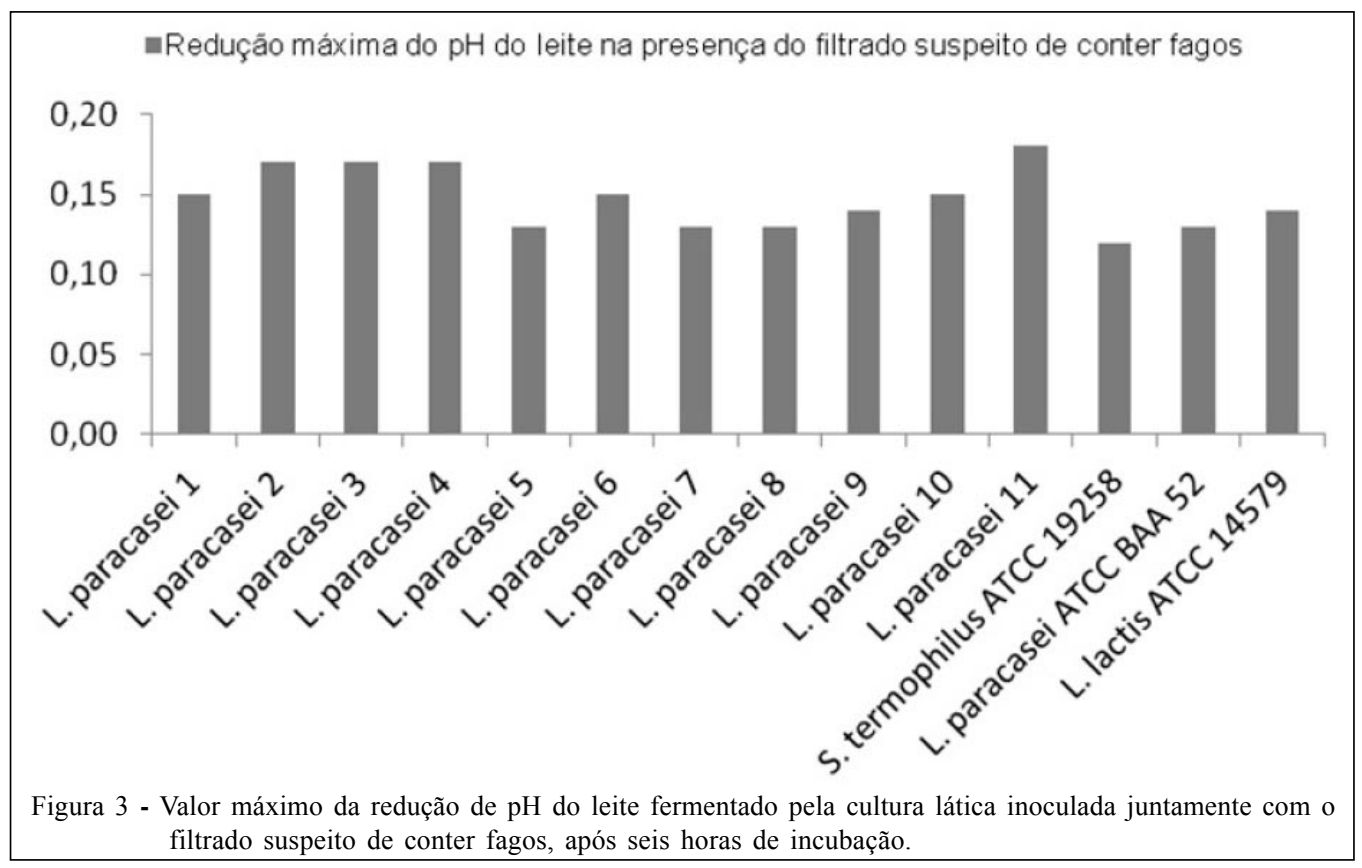

bacteriófagos, indicando que todos os microorganismos testados, incluindo as cepas selvagens demonstraram ser resistentes aos bacteriófagos avaliados, corroborando os resultados obtidos nos teste de produção de ácido e nos testes de lise celular. Nesse mesmo teste, também foi observado que não havia agentes inibidores (antibióticos, por exemplo) nas amostras de leite, soro e queijo de Coalho coletadas nas quatro Unidades de processamento, uma vez que todas as culturas testadas, quando inoculadas com os filtrados tratados termicamente apresentaram o mesmo crescimento (turbidez) do controle.

As 11 cepas de Lactobacillus paracasei pertencentes à Coleção de Micro-organismos da Embrapa Agroindústria Tropical mostraram ser resistentes aos oito diferentes bacteriófagos específicos para L. paracasei da Coleção do INLAIN (Tabela 1).

A característica de resistência destas bactérias tanto aos fagos selvagens (do seu ambiente de processamento) como aos bacteriófagos isolados de um ambiente distinto (bacteriófagos da Coleção do INLAIN) é bastante positiva, uma vez que a indústria apresenta interesse e necessidade constantes em buscar culturas láticas resistentes a bacteriófagos para fabricação de produtos lácteos fermentados. Dessa forma, esta pesquisa contribuiu para a seleção de microorganismos visando à elaboração de um fermento lático adequado à fabricação de queijo de Coalho a partir de leite pasteurizado.

\section{CONCLUSÃO}

As bactérias ácido-láticas de referência e as onze cepas de Lactobacillus paracasei, pertencentes à Coleção de Micro-organismos da Embrapa Agroindústria Tropical, foram resistentes aos bacteriófagos selvagens presentes nas amostras de leite, soro e queijo de Coalho avaliadas. Além disso, as 11 cepas de $\boldsymbol{L}$. paracasei também foram resistentes aos fagos específicos (INLAIN) para esta espécie.

A característica de resistência a bacteriófagos apresentada pelas 11 cepas de $\boldsymbol{L}$. paracasei as classificam como promissoras para serem avaliadas na composição de um fermento lático especificamente destinado para a fabricação de queijo de Coalho a partir de leite pasteurizado.

\section{AGRADECIMENTOS}

Os autores agradecem ao Conselho Nacional de Desenvolvimento Científico e Tecnológico (CNPq), pela concessão da bolsa de Mestrado e, ao Instituto de Lactología Industrial (INLAIN), pela oportunidade de realização dos testes com fagos específicos.

\section{REFERÊNCIAS}

ALLISON, G.E.; KLAENHAMMER, T.R. Phage resistence mechanism in lactic acid bacteria. International Dairy Journal, v.8, p.207-226, 1998. Disponível em: <http:// ww w. sciencedirect . com/science/article/pi i/ S0958694698000430>. Acesso em: 19 set. 2011. doi: 10.1016/ S0958-6946(98)00043-0. 
ALLWOOD, P.B. et al. Occurrence of Escherichia coli, noroviruses, and F-specific coliphages in fresh market-ready produce. Journal Food Protection, v.67, n.11, p.2387-2390, 2004. Disponivel em: <http://www.ncbi.nlm.nih.gov/pubmed/ 15553617>. Acesso em: 19 set. 2011.

ASSOCIATION OF OFFICIAL ANALYTICAL CHEMISTS AOAC. Official Methods of Analysis of AOAC International. 16 ed. Gaithersburg: AOAC International, 1997. $1141 \mathrm{p}$.

BRUNO, L.M. et al. Isolamento e identificação preliminar de bactérias ácido láticas de leite e queijo de coalho. In: CONGRESSO BRASILEIRO DE CIÊNCIA E TECNOLOGIA DE ALIMENTOS, 19., 2004, Recife, PE. Anais... Recife, PE: SBCTA, 2004. CD-ROM.

CAPRA, M.L. Bacteriofagos de Lactobacillus casei/ paracasei. Caracterización y estudio de la fagorresistencia. 2007. 249f. Dissertação (Mestrado em Ciência e Tecnologia de Alimentos) - Faculdade de Engenharia Química, Universidade Nacional do Litoral. Santa Fé, Argentina.

CARVALHO, J.D.G. Caracterização da microbiota lática isolada de queijo de coalho artesanal produzido no Ceará e de suas propriedades tecnológicas. 2007. 154f. Tese (Doutorado em Tecnologia de Alimentos) - Departamento de Tecnologia de Alimentos, Universidade Estadual de Campinas, SP.

GUGLIELMOTTI, D.M. et al. Streptococcus thermophilus phage monitoring in a cheese factory: Phage characteristics and starter sensitivity. International Dairy Journal, v.19, n.8, p.476-480, 2009. Disponível em: <http:// www.sciencedirect.com/science/article/pii/ S0958694609000375>. Acesso em: 19 set. 2011. doi:10.1016/ j.idairyj.2009.02.009.

HAGENS, S.; OFFERHAUS, M.L. Bacteriophages - New weapons for food safety. Food Technology, v.62, n.4, p.4654, 2008. Disponível em: <http://www.ift.org/food-technology/ past-issues/2008/april/features/bacteriophages-new-weaponsfor-food-safety.aspx>. Acesso em: 19 set. 2011.
MADERA, C. et al. Characterization of technologically proficient wild Lactococcus lactis strains resistant to phage infection. International Journal of Food Microbiology, v.86, n.3, p.213-222, 2003. Disponível em: <http:// www.sciencedirect.com/science/article/pii/ S0168160503000424>. Acesso em: 30 jul. 2011. doi:10.1016/ S0168-1605(03)00042-4.

MALLOVE, Z. Phages: a new means of food safety? Food safety news - Breaking news for everyone's consumption. 21 maio, 2010. Acesso em: 20 set. 2011. Online. Disponível em: <http://www.foodsafetynews.com/2010/ 05/phages-a-new-means-of-food-safety/>.

O'FLYNN, G. et al. Evaluation of a cocktail of three bacteriophages for biocontrol of Escherichia coli O157:H7. Applied and Environmental Microbiology, v.70, n.6, p.3417-3424, 2004. Disponível em: <http://aem.asm.org/cgi/ reprint/70/6/3417>. Acesso em: 19 set. 2011. doi: 10.1128/ AEM.70.6.3417-3424.2004.

PIARD, J-C. et al. Bactérias láticas. Biotecnologia Ciência \& Desenvolvimento, v.II, n.8, p.80-84, 1999. Disponível em: $\quad<$ http://www.biotecnologia.com.br/revista/bio08/ bio_8.pdf>. Acesso em: 19 set. 2011.

QUIBERONI, A. et al. Comparative analysis of Streptococcus thermophilus bacteriophages isolated from a yogurt industrial plant. Food Microbiology, v.20, n.4, p.461-469, 2003. Disponível em: <http://www.sciencedirect.com/science/article/ pii/S0740002002001430>. Acesso em: 19 set. 2011. doi:10.1016/S0740-0020(02)00143-0.

QUIBERONI, A. et al. Streptococcus thermophilus bacteriophages. International Dairy Journal, v.20, n.10, p.657-664, 2010. Disponível em: <http:// www.sciencedirect.com/science/article/pii/ S0958694610000932>. Acesso em: 19 set. 2011. doi:10.1016/ j.idairyj.2010.03.012.

SVENSSON, U.; CHRISTIANSON, A. Methods for phage monitoring. Bulletin of International Dairy Federation, Brussels, v.263, p.29-39, 1991. 